\title{
DEMOCRACIA: CIDADANIA E SEUS LIMITES ${ }^{1}$ DEMOCRACY: CITIZENSHIP AND ITS LIMITS
}

Francioli Bagatin ${ }^{2}$

\begin{abstract}
RESUMO: A Democracia é certamente um dos temas mais caros às Ciências Sociais. Embora tenha como fundamentos a igualdade e a liberdade ela apresenta limites, seja no país onde foi criada, seja no Brasil, cuja experiência democrática é muito recente. Entender as limitações da democracia é fundamental para sua consolidação ampla e efetiva, garantindo aos cidadãos, através de seus direitos (civis, políticos e sociais) a igualdade e a liberdade, independente de diferenças de gênero, classe social, etnia ou religião. Partindo do conceito de cidadania proposto por T. H. Marshall, o que se pretende é fazer um resgate do conceito de cidadania e relacioná-lo à democracia e as suas limitações, pois mesmo que a democracia tenha um aspecto de universalidade esta não atinge igualmente a todos, permitindo a ocorrência de desigualdades. A democracia moderna aliou-se de maneira consistente ao sistema capitalista e é tida como o único sistema de governo compatível com o capitalismo. Feministas, marxistas e multiculturalistas promoveram críticas ao ideal de cidadania proposto por Marshall e alertam para as consequências desse alinhamento produzido entre democracia e capitalismo, que gerou esta forma de sociedade: "democrática", capitalista e liberal, caracterizada pela desigualdade de classes, baseada numa democracia abstrata e formal.
\end{abstract}

PALAVRAS-CHAVE: Cidadania; Democracia; Minorias.

ABSTRACT: Democracy is certainly one of those themes dear to the Social Sciences. Although based on equality and freedom, democracy has limits, either in the country where it was created or in Brazil, whose democratic experience is very recent. Understanding the limitations of democracy is fundamental for its wide and effective consolidation, guaranteeing to citizens, through their rights (civil, political and social), equality and freedom, independent of gender, social class, ethnicity or religion differences. From the concept of citizenship proposed by TH Marshall, it is intended to make a rescue of the concept of citizenship and then relate it to democracy and its limitations, because even if democracy has an aspect of universality this does not reach equally everyone, allowing the occurrence of inequalities. Modern democracy has consistently aligned itself with the capitalist system and it is accepted as the only system of government compatible with capitalism. Feminists, marxists and multiculturalists criticized Marshall's ideal of citizenship and warned about the consequences of this alignment between democracy and capitalism, which created this kind of society: "democratic", capitalist and liberal, characterized by class inequality, based on an abstract and formal democracy.

KEYWORDS: Citizenship; Democracy; Minorities.

\footnotetext{
${ }^{1}$ Trabalho desenvolvido como conclusão da disciplina Democracia, Participação e Políticas Públicas no Programa de Pós-graduação em Ciências Sociais (PPGCS) - nível Mestrado, na linha de pesquisa Democracia e Politicas Publicas - Unioeste (Campus Toledo).

${ }^{2}$ Mestranda em Ciências Sociais na UNIOESTE desde 2016. Graduada em Ciências Sociais (Bacharelado) pela UNIOESTE/2016. Graduada em Ciências Sociais (Licenciatura) pela UNIOESTE/2015. Especialista em Planejamento, Gestão e Avaliação de Políticas Públicas pela UNIOESTE/2013. Graduada em Direito pela Universidade Paranaense UNIPAR/1998. Especialista em Direito Processual Civil pela UFPR/2001. franbng@hotmail.com.
} 


\section{INTRODUÇÃO}

Diversas manifestações populares vêm ocorrendo no Brasil desde 2013, contra a corrupção, contra as reformas trabalhistas e previdenciárias, e contra o Governo Federal, especificamente contra o governo da ex-presidenta Dilma Roussef, afastada de seu mandato mediante a aprovação de impeachment em 2016. A partir de tais eventos muito se tem discutido sobre democracia e cidadania, em especial no que se refere à participação política do povo brasileiro e seu direito à liberdade de expressão. Não há como desvincularmos ambos os conceitos - democracia e cidadania - pois estão intrinsicamente relacionados, prescindindo a democracia do ideal de cidadania para existir e por isso mesmo interessa entender como se constituíram estes ideais.

Parto da análise do conceito de cidadania proposto por T. H. Marshall e as críticas que foram produzidas a este conceito, críticas estas contundentes e necessárias, por tratar-se, como veremos, de um conceito excludente das diferenças, e não um conceito inclusivo, em que todos os indivíduos são considerados como iguais. A igualdade acaba sendo determinante apenas no plano formal, não tendo alcance efetivo a todos; e a cidadania tem reflexos diferentes sobre as classes sociais, em que pese ter um caráter de igualdade, há predominância de uma classe social sobre outra, permitida pela democracia moderna que, somada ao capitalismo, gerou um sistema de desigualdades, baseado num conjunto de ideais, crenças e valores que se tornam opostos entre as classes sociais, as quais são, por sua natureza e constituição, antagônicas.

\section{O CONCEITO DE CIDADANIA SEGUNDO T. H. MARSHALL}

O conceito de cidadania é cunhado por T. H. Marshall na obra "Cidadania, Classe e Status" (1967), dentro dos limites do liberalismo econômico presente na sociedade inglesa dos séculos XVIII, XIX e XX. Define cidadania como a participação integral do indivíduo na comunidade, ou seja, "cidadania é um status concedido àqueles que são membros integrais de uma comunidade. Todos aqueles que possuem o status são iguais com respeito aos direitos e obrigações pertinentes ao status" (MARSHALL, 1967, p. 76). Entretanto, essa cidadania prescinde da interferência do Estado para a garantia dos direitos dos cidadãos, e para serem admitidos como cidadãos os indivíduos têm que ser considerados como iguais, elevando a cidadania, dentro dos moldes liberais, ao arcabouço da desigualdade social legitimada. 
A análise de Marshall (1967) divide o conceito de cidadania em três partes ${ }^{3}$, divisão que se tornaria uma referência clássica nos estudos de cidadania: (1) direitos civis, que teriam se consolidado no século XVIII; (2) direitos políticos, que teriam se consolidado no século XIX; e (3) direitos sociais, consolidados no século XX. Para ele, o surgimento dos direitos civis visa a garantia dos direitos individuais, como a liberdade de ir e vir, ou mesmo o direito de trabalhar, e conforme iam se implantando novos direitos individuais, cidadania se torna sinônimo de liberdade. Porém, é fato que estes direitos civis eram garantidos de forma restrita, legitimados apenas aos membros adultos da comunidade, especificamente aos membros do sexo masculino, e às mulheres cabia um status diferenciado - nas palavras de Marshall: “peculiar” - (MARSHALL, 1967, p.68). Quanto aos direitos políticos, apresentariam um caráter de extensão e incorporação: extensão de direitos já existentes a novos setores da população, como o direito de voto que foi estendido à classe operária, uma vez o direito de voto era monopólio restrito de uma classe social determinada. Mas, ainda que estendido a certa parcela da população até então excluída, permanece seu caráter censitário, não sendo extensivo às mulheres e também, pelo fato de que a igualdade política não é atingida, persistindo remanescentes de desigualdade com base em diferenças de substrato econômico (MARSHALL, p. 70). No que pertine aos direitos sociais, Marshall afirma que estariam entrelaçados aos direitos políticos: na idade média os direitos sociais estariam inseridos nas próprias comunidades locais e associações funcionais, as quais, como garantidoras desses direitos foram progressivamente substituídas pela figura do Estado. A conclusão de Marshall é que houve a necessidade de intervenção do Estado para a garantia desses direitos ante à nova realidade econômica capitalista (a regulação do mercado e das relações trabalhistas), pois o que se quer mediante a regulamentação da nova situação pelo Estado é garantir que os indivíduos sejam adequados (minimamente) a condição de cidadãos ${ }^{4}$.

Marshall não deixa de perceber em sua análise certos limites da democracia, e que a cidadania tem reflexos diferentes sobre as classes sociais, pois apesar da cidadania ter um caráter de igualdade, por sua vez a existência de classes sociais tem caráter fundamental de desigualdade. Podemos dizer inclusive que, embora houvessem desigualdades nas sociedades antigas e durante a vigência do sistema feudal, na sociedade capitalista que surge a partir do século XIV esta desigualdade persiste através do ideal de democracia, sistema político

\footnotetext{
${ }^{3}$ Ao desdobrar essa separação funcional em três momentos Marshall faz uma ressalva: os referidos períodos constitutivos dessas esferas de direito, embora possam ser demarcadas no tempo, não deve ser feito de forma rígida, pois há um entrelaçamento entre tais esferas.

${ }^{4}$ Sobre o papel do Estado para implantação do capitalismo ver WOOD, Ellen Meiksins. Democracia contra Capitalismo: a renovação do materialismo histórico. Editora Boitempo. São Paulo, 2003.
} 
vigente, somado ao capitalismo, sistemas estes que se baseiam num conjunto de ideais, crenças e valores que, embora "universais", se tornam opostos entre estas classes sociais, conservando-se as desigualdades.

\section{CRÍTICAS AO CONCEITO DE CIDANIA}

Diversas críticas foram feitas ao conceito de cidadania proposto por Marshall (1967), principalmente no que se refere à sua efetividade. Entre seus críticos podemos citar Reinhard Bendix, Iris Marion Young, Will Kymlicka, Décio Saes, e Ellen Meiksins Wood entre outros.

Bendix afirma que os direitos de cidadania surgem juntamente com o Estado Nação, e se toram um símbolo de igualdade de âmbito nacional, com a possibilidade de uma participação ativa das classes baixas no âmbito da política (BENDIX, 1996, p 135). Entretanto, sublinha com propriedade que ao mesmo tempo em que os direitos de cidadania surgem com a ideia de igualdade de todos perante a lei, isso somente ocorre no plano formal. Ou seja, a igualdade é legal, porém subsiste ao lado de uma desigualdade social e econômica, e essa igualdade formal beneficia àqueles que possuem independência social e econômica, $o$ que lhes possibilita tirar proveito de seus direitos legais. Aos demais, cabe o direito de tentar corrigir as desigualdades (valendo-se do princípio da igualdade), porém “a extensão da cidadania às classes baixas envolve em muitos níveis a institucionalização do critério de igualdade abstrato que dá origem tanto a novas desigualdades como a novas medidas para lidar com essas consequências subordinadas" (BENDIX, 1996, p.138).

Partindo da ótica dos direitos de cidadania e de sua lógica da igualdade, críticas de diversas naturezas questionam esse ideal de cidadania, um conceito excludente das diferenças, e não um conceito inclusivo, para o qual todos são iguais, e a igualdade acaba sendo determinante apenas no plano formal, não atingindo efetivamente a todos.

\section{AS CRÍTICAS FEMINISTA E MULTICULTURAL}

Iris M. Young produz uma crítica, de natureza feminista, ao conceito de cidadania de Marshall. Seus questionamentos sobre o alcance da cidadania (ou seus limites) se iniciam através da discussão do ideal da imparcialidade, para o qual a igualdade pressupõe, para as mais diversas situações, uma análise imparcial e impessoal dos fatos, desconsiderando todos e quaisquer interesses particulares, valendo-se dos princípios gerais de justiça e de direito para atingir a referida imparcialidade. Nesse caso, a imparcialidade somente seria possível de ser 
atingida abstraindo-se da realidade todas as particularidades de cada situação, uma vez que as particularidades é que são determinantes das diferenças entre os indivíduos (YOUNG, 2012, p. 169). Ou seja, para a existência do ideal de imparcialidade a lógica é reduzir as diferenças para atingir a unidade, prestando-se a um papel ideológico, cujo objetivo é "mascarar as formas pelas quais as perspectivas particulares de grupos dominantes reivindicam universalidade e colaboram para justificar estruturas hierárquicas de decisão" (YOUNG, 2012, p. 171).

Se para existir a igualdade deve-se transcender as particularidades para a busca de um bem comum, o ideal cívico opera para excluir as pessoas que estariam associadas à esfera privada, e, portanto, dissociadas do âmbito público, que requer a moral ilibada e o sufocamento das paixões e sentimentos em nome da razão. Deste modo, para Young, o sentido de "público" prescinde ser modificado para expor a positividade das diferenças de grupo, da paixão e do lúdico (YOUNG, 2012, p. 171). Esta ideia de igualdade, de unidade, persiste ante a lógica da identidade, onde as coisas devem ser pensadas em conjunto e reduzidas à unidade, valendo-se da construção de sistemas totalizantes, reduzindo tudo a um princípio ideal. Ou seja, a lógica da identidade ${ }^{5}$ nega ou reprime as diferenças. (YOUNG, 2012, p. 172)

Para Young o surgimento do Estado moderno é preponderante para a ocorrência de desigualdades, e destaca que para este Estado o ponto de vista universal coletivo deve ser imperativo - ser cidadão é expressar a nobreza humana e a liberdade genuína colocando o interesse coletivo acima dos interesses pessoais, o que por sua vez não é compatível com a satisfação dos desejos pessoais. O ideal do público cívico é então excludente, uma vez que a homogeneidade do público cívico retira do público todos os indivíduos e grupos que não se encaixam no modelo de cidadão racional, capaz de transcender corpo e sentimento. Ao mencionar os indivíduos e grupos excluídos percebe-se que se excluem as diferenças relativas ao gênero, etnia, idade, pois os aspectos corporais, sexuais, incertos e desordenados estariam identificados com mulheres, homossexuais, negros, índios, judeus e orientais (YOUNG, 2012, p. 185).

A crítica de Young visa justamente mostrar que o ideal do público cívico deve ser revisto, deve ser feita uma reconceituação do público e do privado, e da relação que se estabelece entre eles. O "público" deve ser aberto e acessível, uma esfera pública que não seja

\footnotetext{
${ }^{5}$ A lógica da identidade deriva do ideal de imparcialidade à medida que se abstraem todas as particularidades com objetivo de atingir (ou justificar) o ideal de igualdade.
} 
excludente, onde não se pressupõe a adoção de um ponto de vista geral ou universal, no sentido de que devem ser aceitas as diferenças em relação a etnia, gênero, idade, entre outros, pois a justiça não deve se opor a necessidade, sentimento e desejos pessoais, as quais ocorrem justamente através das diferenças, de modo que não se atingirá o ideal da verdadeira justiça enquanto não observadas as particularidades de cada caso.

A crítica multicultural foi construída por Will Kymlicka (2011) sobre a fundamentação de que os princípios gerais dos direitos humanos são incapazes de proteger as minorias nacionais contra injustiças, uma vez que os direitos humanos deveriam ser suficientes para garantir a justiça entre grupos etnoculturais em um Estado multiétnico. E, segundo Kymlicka, isto não ocorre devido à incapacidade dos direitos humanos em proteger as minorias nacionais em detrimento do interesse da maioria. De maneira similar ao fundamento observado na crítica feminista, trata-se das minorias e de seus direitos, e por consequência, de grupos excluídos do alcance dos direitos de cidadania Nesse caso, os direitos humanos seriam universais e indivisíveis (fato ao qual não se opõe), entretanto, faz ressalva ao fato de que para que os direitos humanos sejam efetivos a justiça etnocultural deve ser respeitada, concluindo que o "impacto dos direitos humanos depende do nível de respeito aos outros princípios de justiça etnocultural” (KYMLICKA, 2011, p. 15-16).

A profundidade de Kymlicka pode ser percebida quando apresenta a dicotomia entre direitos individuais e direitos coletivos, no sentido de que, na visão hegemônica, direitos humanos consistem nos próprios direitos individuais, típicos das sociedades ocidentais que pregam o individualismo (sociedade euroamericana). Ao contrário, em sociedades não euroamericanas os direitos estariam vinculados à ideia de direitos coletivos ou de grupo (KYMLICKA, 2011, p. 17). Esse individualismo está diretamente relacionado às sociedades liberais, fundamentadas na igualdade, porém, e de maneira argumentativa próxima a de Young, Kymlicka nos coloca que dentro dessa filosofia individualista, para que haja igualdade devem ser suprimidas todas as referências aos direitos de minorias étnicas e nacionais, ou seja, deve criar-se uma homogeneidade de indivíduos. Dentro dessa ideologia liberal certos elementos colaboram para que os direitos humanos não consigam proteger os direitos das minorias, tanto é assim que, nessa perspectiva, o Estado trata de desapoderar as minorias e destruir suas instituições coletivas e seu poder político, sem, no entanto, interferir nos direitos civis e políticos desses indivíduos.

Para Kymlicka o que piora a situação da incapacidade de os direitos humanos protegerem os direitos das minorias é que muitas vezes "as normas de direitos humanos são 
insuficientes para evitar a injustiça etnocultural e podem, na verdade, acabar piorando a situação" (KYMLICKA, 2011, p. 34), pois por vezes acabam se prestando, ainda que indiretamente, a serem instrumento de colonização, como instrumento da legitimação de uma dominação injusta. Para haver justiça, e serem efetivamente direitos humanos, tais direitos devem ser complementados com os vários direitos das minorias (língua, autogoverno, direito de representação), assegurando-se primeiramente o respeito aos direitos humanos individuais e asseguradas as condições para um debate livre e democrático para tratar das questões envolvendo os direitos das minorias. Não se trata de excluir um em detrimento do outro, mas de coexistirem de modo a garantir os direitos das minorias inclusive; devem "os direitos humanos e os direitos de as minorias serem tratados de forma conjunta, como componentes igualmente importantes de uma sociedade justa" (KYMLICKA, 2011, p. 36).

Apesar de ter a convicção de que os direitos humanos devem coexistir e serem complementados pelos direitos das minorias, Kymlicka não deixa de observar que haveria uma grande dificuldade de codificar esses direitos das minorias em nível internacional, ante a ampla realidade de minorias diversas umas das outras. Não seria caso de se falar em universalização dos direitos das minorias, sendo que essa universalização estaria restrita aos direitos humanos propriamente ditos, pois as minorias se apresentam em diversos formatos e tamanhos (minorias nacionais, povos indígenas, imigrantes). Dessa forma, para o autor, da relação entre as minorias que querem seus direitos respeitados e os direitos humanos a serem aplicados e a maioria que não reconhece a diversidade decorriam diferenças insuperáveis, uma vez que as minorias (e também a maioria) dificilmente aceitariam um mínimo denominador comum que satisfaça a todos equitativamente. $\mathrm{O}$ que se deve reconhecer é que os direitos humanos são ineficientes para a proteção dos direitos das minorias, e ao mesmo tempo, reconhecer a necessidade de complementá-los de maneira mais adequada em cada país (KYMLICKA, 2011, p. 40).

Da mesma forma, como na crítica feminista, percebe-se que a crítica multicultural se refere à maioria como sendo fruto de uma cultura branca, burguesa, masculina e etnocêntrica, o que exclui da esfera de proteção e atuação dos direitos de cidadania todos os indivíduos que estejam fora dessa padronização (mulheres, homossexuais, indígenas, orientais, judeus, entre outros, constituintes das minorias étnicas, religiosas, entre outras).

\section{A CRÍTICA MARXISTA}


Os marxistas não podiam deixar de produzir sua crítica ao conceito de cidadania, sendo que o próprio Marx teria definido democracia não como forma de governo, mas a partir da noção de Estado, principalmente no que pertine as "diferenças entre o Estado capitalista e o Estado no período de transição pós-revolução. Décio Saes constrói sua crítica a partir do conceito clássico de Marshall de cidadania e de como essa cidadania evoluiu numa sociedade capitalista, enfatizando sua análise sobre o aspecto da cidadania política daí derivado. Ellen Meiksins Wood, historiadora marxista, também constrói sua crítica à democracia liberal e ao conceito de cidadania dela derivado, expondo sua tese na obra "Democracia contra Capitalismo - a renovação do materialismo histórico" (2003), na qual o capitalismo e a democracia são incompatíveis, e de que modo o capitalismo se desenvolve possibilitando o surgimento da democracia moderna.

Saes (2003) critica o fato de que, apesar da relevância de sua obra, Marshall não define efetivamente o que é cidadania, considerando sua definição vaga e obscura, uma vez que o mais próximo de definição do conceito seria a ideia de que cidadania é a participação integral do indivíduo na comunidade política. Por sua vez, Saes tampouco apresenta um conceito de cidadania que possa substituir o conceito marshalliano. A crítica de Saes se refere a princípio, à ideia de evolução dos direitos presente no conceito marshalliano e que essa a evolução teria ocorrido de forma natura, porém, o aspecto mais relevante da crítica de Sae se refere ao fato de que Marshall teria desconsiderado totalmente que, para a implantação dos direitos de cidadania, a luta de classes e a participação da classe trabalhadora teria sido preponderante, e determinante, na conquista dos direitos políticos e sociais. Marshall teria subestimado o processo revolucionário no processo de instauração da cidadania, uma vez que para atingir a democracia completa seria necessário a transformação social radical, a qual não teria ocorrido sem a participação de uma classe trabalhadora em conflito com uma classe dominante, e que teria como consequência um rearranjo das instituições, garantindo então os direitos políticos e socais buscados (SAES, 2003, p. 13). Na visão de Marshall essa evolução da cidadania seria natural se pensada como decorrente da própria constituição do capitalismo, ou seja, seria a evolução do capitalismo que teria propiciado as condições para esta evolução natural da cidadania, na forma que se deu no modelo inglês. Porém, tanto para Saes quanto para outros críticos de Marshall, essa concepção evolutiva da cidadania deve ser considerada "idílica e excessivamente otimista" justamente porque Marshall subestima a resistência das classes dominantes e da burocracia estatal à ampliação do elenco de direitos individuais, postura essa que pode ser considerada estagnacionista ou mesmo regressiva, ao contrário do 
que se percebe na postura das classes trabalhadoras, as quais (ainda que não analisadas no contexto marshalliano) tem uma atitude dinâmica e progressiva nessa ampliação de direitos (SAES, 2003, p. 16). É essa relação de oposição entre o caráter estagnacionista/regressivo por parte da classe dominante versus o caráter dinâmico/progressivo por parte da classe trabalhadora que dá ao processo de criação dos direitos na sociedade capitalista um caráter conflituoso, e não meramente evolutivo como pensara Marshall. Embora esse processo não possa ser considerado contraditório, uma vez que, mesmo na medida de refutarem a extensão de direitos à classe trabalhadora, ainda assim a classe dominante cede e os estende, e nesse ponto é que foi fundamental a postura dessa classe trabalhadora pois tal concessão não se dá de forma imotivada e desinteressada. Por outro lado, a totalidade de direitos conquistados pelas classes trabalhadoras infelizmente não altera as relações estabelecidas entre as classes sociais, pois o sistema capitalista não é colocado em xeque pela concessão de direitos de cidadania aos trabalhadores.

Partindo desse ponto, de que a totalidade de direitos conquistados pelas classes trabalhadoras infelizmente não altera as relações estabelecidas entre as classes sociais, pois o sistema capitalista não é colocado em xeque pela concessão de direitos de cidadania aos trabalhadores, é que nos aproximamos de uma crítica ao conceito de cidadania e o que ele representa na visão de Ellen Meiksins Wood. Para ela, o capitalismo e democracia são incompatíveis, e é o capitalismo que possibilita o surgimento da democracia moderna. Um dos fatores que, segundo Wood (2003) teria possibilitado o desenvolvimento da democracia moderna com as características que tem hoje (democracia passiva, universalista, abstrata, exercida por um governo do povo mediante representação, com cidadãos expropriados por meios econômicos e sem identidade social) foi a separação entre as esferas econômica e política com o surgimento do modo de produção capitalista (WOOD, 2003). E é justamente esse argumento de que existe a separação entre as esferas econômica e política que, segundo os economistas político burgueses, demonstram a eternidade e a harmonia das relações sociais (WOOD, 2003, p. 29).

É com base nesta separação entre as esferas econômica e política que para Wood (2003), o capitalismo permite o surgimento da democracia moderna na forma como existe hoje: (1) mais inclusiva e universalista do que a ateniense estando mais próxima da ideia de cidadania romana; (2) mais inclusiva e universalista porque pode ser estendida aos estrangeiros e há uma distância maior entre o povo e a esfera da ação política - uma ligação menos imediata entre cidadãos e participação política; (3) e ao mesmo tempo é mais abstrata e 
mais passiva, tendo como objetivo, através da representação, distanciar o povo da política, através da ideia de soberania popular, o que dá novo sentido à definição de cidadania, na qual há um esvaziamento completo de todo o conteúdo social do conceito de democracia e um conceito político de povo de que foram suprimidas as conotações sociais (WOOD, 2003, p. 190).

É interessante observar que democracia, na realidade ateniense, tinha um sentido social, o demos ${ }^{6}$ no seu sentido social, relacionado também às classes inferiores ou pobres: seria um governo de muito ao invés de poucos, e não um governo de classe. E nesse caso, uma pólis que fosse governada por uma comunidade política que não incluísse o demos em seu significado social não seria uma democracia. Democracia seria o governo de muitos, inclusive dos pobres e era considerada uma democracia justamente por promover a inclusão dos pobres nas deliberações políticas e econômicas da sociedade. Os federalistas ao resgatarem a ideia de povo como categoria política o fizeram não com objetivo de afirmar os direitos contra aqueles que gostariam de excluir da esfera pública, ao contrário, o objetivo era diluir o poder na multidão popular principalmente em defesa da propriedade. Aqui o critério de classe não representa um critério de democracia - não há na democracia americana uma limitação censitária como existia em Atenas, mas ainda assim os americanos a fizeram indiretamente: deslocaram a democracia para uma esfera puramente política, distinta e separada da sociedade civil, ou seja, a economia. Desta forma, a estrutura social do capitalismo altera o significado de cidadania, em que a universalidade dos direitos políticos (sufrágio adulto universal) deixa intacta as relações de propriedade e de poder. O capitalismo torna possível uma forma de democracia em que a igualdade formal de direitos políticos tem efeito mínimo sobre as desigualdades ou sobre as relações de dominação e de exploração em outras esferas.

Se pensarmos em governo do povo, temos que pensar que todo indivíduo deve ser livre, mas no sentido de liberdade que era utilizado pela democracia ateniense, a qual, apesar de censitária, prescindia de homens livres, que não estavam sujeitos à extração econômica do excedente de sua produção. Livres e iguais, igualdade no sentido de que os cidadãos tinham capacidade para participar da esfera política $^{7}$, que em Atenas não era separada da esfera econômica. A democracia moderna permitiu que a cidadania fosse estendida a todos (aí

\footnotetext{
${ }^{6} \mathrm{O}$ demos tinha um significado social por ser deliberadamente oposta à exclusão das classes inferiores da política.

$7 \mathrm{Na}$ democracia ateniense odos os cidadãos podiam e deviam participar das assembleias, decidindo sobre qualquer assunto, e odos tinham o poder de falar em condições de igualdade com seus pares.
} 
incluídas mulheres, minorias, etc.) justamente pela separação entre a esfera política e a econômica, pois ainda que mediante a representação, assuntos relativos à economia são mantidos fora da esfera política, estando consequentemente fora do alcance de atuação da maioria dos cidadãos. O que pertence à esfera da economia vai ser decidido pelos apropriadores e tudo o que diz respeito à produção está fora do alcance dos produtores. Ao cidadão, que é ao mesmo tempo produtor, somente cabem os direitos políticos: votar e ser votado (com ênfase no votar), pois a partir de constituída a representação, os cidadãos não têm mais o direito à isegoria, a manifestar-se com igualdade e sobre qualquer assunto.

Outro aspecto apresentado por Wood (2003) e que vem ao encontro das críticas feminista e multiculturalista já mencionadas diz respeito ao fato de que, para ela, a discussão sobre a emancipação humana não está mais restrita ao campo econômico e à luta de classes, sendo que a disputa teria se transferido para o campo denominado de "bens extraeconômicos", os quais dizem respeito à emancipação de gênero, igualdade racial, paz, saúde ecológica e cidadania democrática, e ainda, que o "projeto socialista de emancipação de classe sempre foi, ou deveria ter sido, um meio para o objetivo maior da emancipação humana" (WOOD, 2003, p. 227). As críticas de Wood ao capitalismo são muito expressivas, sendo que os bens extraeconômicos não seriam compatíveis com o capitalismo e um dos maiores problemas que identifica é a questão da universalidade, ou a falta de identidade social específica destas forças sociais (WOOD, 2003, p. 228). Quando fala em raça ou gênero, falar em anti-racismo e anti-sexismo é caso de identidades sociais muito específicas, que geram forças sociais vigorosas (WOOD, 2003, p. 229), e a grande questão que se coloca é como tais forças sociais se relacionam com o capitalismo, se são ou não compatíveis, e de que maneira afetam a democracia e a cidadania.

Wood é categórica ao afirmar que uma característica do capitalismo é ser indiferente às identidades sociais das pessoas que explora: não se liga à identidades, desigualdades e muito menos às diferenças extraeconômicas políticas ou jurídicas, ou seja, sua tendência é ocultar as diferenças e fluidificar as identidades (gênero e raça), pois a lógica do capital é absorver as pessoas no mercado de trabalho e promover a redução destas a unidades intercambiáveis de trabalho, privadas de quaisquer identidades específicas. O capitalismo promove a universalidade ao mesmo tempo em que produz e se utiliza de forças que promovem opressões sociais particulares (WOOD, 2003, p. 229). Sua grande crítica ao capitalismo é que ele interfere diretamente nas relações sociais e na cidadania dos indivíduos. E no mesmo sentido da crítica feminista de que a cidadania é promovida em prol da 
universalidade, onde a lógica da identidade nega ou reprime as diferenças, e que segundo a crítica multiculturalista as diferenças são negadas, reprimidas e suprimidas, para Wood a exploração capitalista se reproduz sem qualquer preocupação com “cor, raça, credo, gênero, ou com a dependência de desigualdade ou diferença extraeconômica; e mais, que isso, o desenvolvimento do capitalismo criou pressões ideológicas contra tais desigualdades e diferenças em grau sem precedentes nas sociedades pré-capitalistas" (WOOD, 2003, p. 229). Sobre racismo e gênero, Wood conclui que

(...) o capitalismo tem uma tendência estrutural a rejeitas as desigualdades extraeconômicas, mas que essa tendência é uma faca de dois gumes. Estrategicamente, ela implica que as lutas concebidas em termos extraeconômicas puramente contra o racismo, ou contra a opressão de gênero, por exemplo - não representam em si um perigo fatal para o capitalismo, que elas podem ser vitoriosas sem desmontar o sistema capitalista, mas que, ao mesmo tempo, terão pouca probabilidade de sair vitoriosas caso se mantenham isoladas da luta anticapitalista (WOOD, 2003, p. 232).

Quanto à questão de a cidadania ser abstrata e formal, além de esvaziada de conteúdo social, Wood, assim como Saes, também vê com restrições à questão do que denomina bens políticos: a participação do cidadão restrita ao direito de votar e ser votado para a eleição de seus representantes, estes sim ativos nas discussões acercas de questões de natureza política e social. O grande empecilho à cidadania ativa e a desvalorização dos bens políticos está relacionada à separação entre o econômico e o político, sendo que o "status dos bens políticos é reduzido pela autonomia da esfera econômica, pela independência da exploração capitalista em relação à execução de funções públicas, pela existência de uma esfera separada e puramente "política" distinta da "economia" (WOOD, 2003, p. 229)", e são estes fatores que permitiram à democracia tornar-se apenas política, desvinculada das esferas econômicas e sociais, , como ocorria na democracia ateniense. Entretanto, ainda que Wood afirme que a democracia formal é incompleta e que a mesma tenha sido possibilitada mediante a separação das esferas econômica e política, essa associação do capitalismo com a democracia formal representa um paradoxo: "é ao mesmo tempo um avanço e um recuo, um aperfeiçoamento e uma desvalorização da democracia". A democracia como é hoje "representa um aperfeiçoamento das formas políticas a que faltam as liberdades civis, o domínio do direito e o princípio da representação" (WOOD, 2003, p. 216), além de representar uma subtração da substância da ideia democrática. Por sua vez, a cidadania, como conceituada por Marshall esbarra na realidade das classes, oriundas do sistema capitalista de produção, e por isso mesmo, expressão das desigualdades entre os indivíduos, pois ainda que direitos políticos 
tenham sido estendidos às classes menos favorecidas e às mulheres, tal participação não tem força para alterar as relações de classe estabelecidas, visto que não interferem diretamente na esfera da produção, a única esfera que se alterada teria repercussão na desigualdade econômica e social.

\section{CONSIDERAÇOES FINAIS}

As críticas ao conceito de cidadania proposto por Marshall são contundentes e necessárias no sentido de que tal definição é insuficiente para a garantia de direitos a todos os indivíduos: é um conceito excludente das diferenças, preconizando e colocando como valor fundamental, a igualdade entre todos os indivíduos.

Longe de considerar a definição de cidadania de Marshall como a melhor, talvez possamos entendê-la como a possível, dentro dos aspectos analisados. Talvez. Mas isso não retira a validade das críticas produzidas ao conceito de cidadania. Ao contrário, o que se buscou através das críticas é, podemos dizer, como concluiu Wood (2003), que a democracia prescinde de conteúdo social, e não deve priorizar a liberdade em detrimento da igualdade. Para Wood, seria possível inclusive, pensar em uma democracia socialista como alternativa à democracia liberal, visto que "a democracia que o socialismo oferece está baseada na reintegração da "economia" à vida política da comunidade, que se inicia pela sua subordinação à autodeterminação democrática dos próprios produtores" (WOOD, 2003, p. 242).

Todas as críticas analisadas reconhecem e reafirmam o caráter limitado da democracia liberal, visto que não atende aos indivíduos da maneira justa e igualitária, e isso significa dizer que as diferenças entre os indivíduos devem ser consideradas na configuração da democracia, dos direitos e da cidadania, pois não há como tratar igualmente os desiguais.

Em outras palavras, após análise da crítica feminista, multicultural e marxista, pode-se afirmar que todas criticam justamente a ideia de igualdade proposta na definição de cidadania marshalliana, a qual apresenta uma visão liberal: a igualdade acima de tudo, o que por si só legitima e justifica as diferenças sociais. E da análise de todas as críticas, analisadas individualmente ou em conjunto, pode-se extrair a conclusão de que o atual conceito de cidadania prescinde ser revisto: basear a cidadania no ideal da imparcialidade e da igualdade gera injustiça, pois para indivíduos com características e necessidades diferentes não há como gerar cidadania e direitos justos como se iguais fossem. 


\section{BIBLIOGRAFIA}

BENDIX, Reinhard. Construção Nacional e Cidadania. Editora da Universidade de São Paulo. São Paulo, 1996. (Obra completa)

KYMLICKA, Will. Direitos humanos e justiça etnocultural. Meritum - Belo Horizonte - v. 6 - n. $2-$ p. 13-55 - jul./dez. 2011. Disponível em http://www.fumec.br/revistas/meritum/article/view/1075. Acesso em 19/09/2015. (Artigo em periódico digital)

MARSHALL, T. S. Cidadania, Classe Social e Status. Editora Zahar. Rio de Janeiro, 1967. (Obra completa)

MOTTA, Luiz Eduardo. A respeito da questão da democracia no marxismo (a polêmica entre Althusser e Poulantzas). Revista Brasileira de Ciência Política, n 13, Brasília, 2014. Disponível em http://www.scielo.br/scielo.php?pid=S0103-

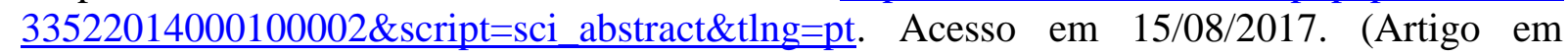
periódico digital)

SAES, Décio Azevedo Marques de. Cidadania e Capitalismo: uma crítica à concepção liberal de cidadania. Crítica Marxista. Vol. 16. 2003. Disponível em http://www.ifch.unicamp.br/criticamarxista/arquivos_biblioteca/artigo93artifo1.pdf. Acesso em 19/09/2015. (Artigo em periódico digital)

YOUNG, Íris Marion. O ideal da imparcialidade e o público cívico. Revista Brasileira de Ciência Política, no 9. Brasília, setembro - dezembro de 2012, pp. 169-203. Disponível em http://periodicos.unb.br/index.php/rbcp/article/view/7748. Acesso em 19/09/2015. (Artigo em periódico digital)

WOOD, Ellen Meiksins. Democracia contra Capitalismo: a renovação do materialismo histórico. Editora Boitempo. São Paulo, 2003. (Obra completa) 